\title{
Organization of Olivocerebellar Activity in the Absence of Excitatory Glutamatergic Input
}

\author{
Eric J. Lang \\ Department of Physiology and Neuroscience, New York University, School of Medicine, New York, New York 10016
}

The olivocerebellar system has been proposed to function as a timing device for motor coordination in which inferior olivary neurons act as coupled oscillators that spontaneously generate rhythmic and synchronous activity. However, the inferior olive receives excitatory afferents, which can also drive the activity of these neurons. The extent to which the olivocerebellar system can intrinsically generate synchronous activity and olivary neurons act as neuronal oscillators has not been determined. To investigate this issue, multiple electrode recordings of complex spike (CS) activity were obtained from 236 crus 2a Purkinje cells in anesthetized rats. Intraolivary injections of the glutamate antagonists 6-cyano-7-nitroquinoxaline-2,3-dione or 1,2,3,4-tetrahydro-6-nitro-2,3-dioxo-benzo[f]quinoxaline-7sulfonamide disodium were made, and the resulting changes in CS activity were determined. Loss of evoked CS responses to motor cortex stimulation or perioral tactile stimulation was used to measure the efficacy of the block. Block of glutamatergic input decreased the average CS firing rate by $\sim 50 \%$ but did not abolish spontaneous CS activity. The remaining CS activity was significantly more rhythmic than that in control. The patterns of synchrony were similar to those found in control conditions (i.e., synchronous CSs primarily occurred among Purkinje cells located within the same $\sim 250-\mu \mathrm{m}$-wide rostrocaudally oriented cortical strip); however, this normal banding pattern was enhanced. These changes in CS activity were not observed with vehicle injections. The results suggest that excitatory afferent activity disrupts olivary oscillations and support the hypotheses that olivary neurons are capable of acting as neuronal oscillators and that synchronous CS activity results from electrotonic coupling of olivary neurons.

Key words: olivocerebellar; synchrony; oscillation; complex spike; inferior olive; CNQX; NBQX
Studies of the olivocerebellar system over the past several decades have demonstrated that this system is capable of generating rhythmic and synchronous complex spike (CS) activity in cerebellar Purkinje cells. Such CS activity has now been demonstrated in both anesthetized and awake, behaving animals of several different species (Bell and Kawasaki, 1972; Llinás and Sasaki, 1989; Sasaki et al., 1989; Welsh et al., 1995; Wylie et al., 1995; Pellerin et al., 1997; Lang et al., 1999) and is central to a proposed role for the olivocerebellar system in motor coordination (Llinás, 1991).

Anatomical and physiological studies of the inferior olive (IO) have suggested that the mechanisms for generating rhythmic and synchronous olivocerebellar activity are intrinsic to the IO. Inferior olivary neurons are electrotonically coupled by numerous gap junctions, providing a potential mechanism for synchronous CS activity (Llinás et al., 1974; Sotelo et al., 1974; de Zeeuw et al., 1989). Moreover, in vitro studies have demonstrated that IO neurons have a complement of membrane conductances that, in conjunction with the electrotonic coupling of IO neurons, support spontaneous subthreshold oscillatory activity, which could underlie the rhythmicity of CS activity (Llinás and Yarom, 1981a,b, 1986; Benardo and Foster, 1986; Bleasel and Pettigrew, 1992; Bal and McCormick, 1997). However, the characteristics of oscilla-

\footnotetext{
Received Oct. 13, 2000; revised Nov. 27, 2000; accepted Dec. 11, 2000.

Funding was provided by the National Institutes of Health-National Institute of Neurological Diseases and Stroke Grant NS-37028 and by National Science Foundation Grant IBN-9808353. I thank D. Paré and T. Casper Lang for their comments on this manuscript.

Correspondence should be addressed to Dr. E. J. Lang, Department of Physiology and Neuroscience, New York University, School of Medicine, 550 First Avenue, New York, NY 10016. E-mail: Lange01@popmail.med.nyu.edu.

Copyright (C) 2001 Society for Neuroscience 0270-6474/01/211663-13\$15.00/0
}

tory activity of IO neurons under in vitro conditions differ in some aspects (oscillation frequency and regularity) from those of CS activity in the intact animal, and despite the high density of gap junctions throughout the IO, synchronous CS activity tends to occur only among small groups of Purkinje cells.

These differences between the in vivo and in vitro results suggest that the patterns of synchronous and rhythmic CS activity reflect not only the intrinsic properties of IO neurons but also the activity of IO afferents. It has been shown previously that inhibitory GABAergic afferents play an important role in modulating these patterns (Llinás and Sasaki, 1989; Lang et al., 1996). The role of excitatory glutamatergic afferents in modulating CS rhythmicity and synchrony has yet to be investigated. However, it is likely that they too play an important role in shaping the patterns of olivocerebellar activity because the IO contains glutamate receptors (Petralia and Wenthold, 1992; Ambalavanar et al., 1998; Paarmann et al., 2000) and receives excitatory projections from numerous CNS regions (Provini et al., 1968; Allen et al., 1974; Oscarsson and Sjölund, 1974; Sasaki et al., 1977; Jeneskog, 1981a,b, 1987). Thus, the present experiments were undertaken to investigate the role of excitatory glutamatergic afferent activity in modulating CS activity and, in particular, to determine whether IO neurons are capable of acting as true neuronal oscillators as hypothesized for their role in motor coordination (Llinás, 1991).

\section{MATERIALS AND METHODS}

Surgery

Extracellular recordings of CS activity were obtained from eight female Sprague Dawley rats (250-300 gm). The rats were initially anesthetized with ketamine (100 mg/kg, i.p.), xylazine $(8 \mathrm{mg} / \mathrm{kg}$, i.p.), and atropine $(0.4 \mathrm{mg} / \mathrm{kg}$, i.p.). In seven animals supplemental doses of ketamine (6 
$\mathrm{mg} / \mathrm{kg}$, i.v.) and xylazine $(0.4 \mathrm{mg} / \mathrm{kg}$, i.v.) were given every $30 \mathrm{~min}$ starting 2-3 hr after the initial dose or as needed to maintain a deep level of anesthesia. In one animal, supplemental anesthesia was applied continuously through the intravenous line at a rate of $\sim 64 \mu \mathrm{g} / \mathrm{min}$ for ketamine and $\sim 1 \mu \mathrm{g} / \mathrm{min}$ for xylazine. The rectal temperature was maintained at $37^{\circ} \mathrm{C}$ by an electric heating pad.

The multiple electrode technique used in the present experiments has been described in detail previously (Sasaki et al., 1989; Sugihara et al., 1993). In brief, after anesthetization the animal was placed in a stereotaxic apparatus, and the occipital bone and dura were removed to expose the dorsal surface of the cerebellum and medulla. A silicon-rubber platform was then cemented in place over crus 2a. Each microelectrode was individually inserted, by the use of a piezoelectric micromanipulator (Burleigh), through the platform into the molecular layer of the cerebellum until CS activity could be recorded. The electrode was then released from the manipulator and held in place by the platform. Successive electrodes were inserted until a rectangular array of 8-10 rostrocaudal columns and 4-6 mediolateral rows, with an interelectrode distance of $250 \mu \mathrm{m}$, was completed. The microelectrodes were implanted to depths of $70-100 \mu \mathrm{m}$ below the cortical surface. At these depths CS activity is readily observed, but simple spike activity is not (simple spike activity typically can be detected starting at depths of 120-150 $\mu \mathrm{m}$ ), thereby allowing the isolated recording of CS activity. After electrode implantation, the threshold for each recording channel was individually set to detect the CS activity. To ensure that only CS activity was detected throughout the recording session, the activity of all electrodes was continuously monitored by the use of a light-emitting diode (LED) panel and oscilloscope. The LED panel consisted of a rectangular array containing one LED for each electrode. Spike activity that crossed the voltage threshold for detection activated the LED corresponding to that electrode. Thus, changes in the activity level of any cell that might occur, such as an increase in baseline noise levels in that channel or the appearance of simple spike activity if the electrode position changed, were immediately detectable as changes in the activity level of the corresponding LED and could then be investigated directly using the oscilloscope. Cells showing such noise or simple spike contamination were eliminated from the data set. Such cells represented only $2 \%$ of the cells ( 5 cells out of 236$)$.

After placement of the recording electrodes, an injection pipette, filled with Ringer's solution, was lowered from the dorsal surface of the medulla to the IO. The correct localization of the pipette tip to the rostral IO was determined by the appearance of IO multiunit activity that was correlated with the CS activity of crus 2a. The location of the injection pipette was also confirmed histologically (see Fig. $1 B$ ).

In some $(n=2)$ experiments, a bipolar stimulation electrode was inserted $\sim 1 \mathrm{~mm}$ into the motor cortex $(2 \mathrm{~mm}$ anterior and $1 \mathrm{~mm}$ lateral to bregma). The evoked CS responses to motor cortical stimuli $(200 \mu \mathrm{sec}$ pulse; $0.5-1.5 \mathrm{~mA}$ ) were used as an independent measure of the efficacy of the intraolivary injections in blocking excitatory input to the olivocerebellar system. In other experiments $(n=4)$, tactile stimulation of the perioral region was used to evoke CS responses and measure the efficacy of the injections. Tactile stimuli were delivered by the use of a stylus ( $\sim$-mm-diameter tip) that was glued to a small audio speaker driven by an amplifier.

\section{Recording and injection procedure}

Extracellular recordings of CS activity were obtained with glass microelectrodes with a tip diameter of $2-5 \mu \mathrm{m}(\sim 5 \mathrm{M} \Omega)$ containing a 1:1 solution of glycerol and $2 \mathrm{M}$ saline. Each session began by obtaining a 20 min baseline recording of spontaneous CS activity. Next, CS responses evoked by stimulation of the motor cortex or perioral region of the face were measured. After recording of the evoked responses, an intraolivary injection was initiated, and the spontaneous and evoked CS activities were recorded.

The procedure for performing pressure injections was modified somewhat from that used previously (Lang et al., 1996, 1997). Here, pressure injections were made using a microdialysis pump (CMA-100; CMA MicroDialysis, Acton, MA) connected to the injection pipette via polyethylene tubing. Continuous injections were made using flow rates of $0.15-0.25$ $\mu \mathrm{l} / \mathrm{min}$. Injection solutions contained one of the following: Ringer's solution, Ringer's solution + 6-cyano-7-nitroquinoxaline-2,3-dione (CNQX; Research Biochemicals-Sigma; $200 \mu \mathrm{M}$ ), or Ringer's solution $+1,2,3,4-$ tetrahydro-6-nitro-2,3-dioxo-benzo[f]quinoxaline-7-sulfonamide disodium (NBQX; Research Biochemicals-Sigma; $200 \mu \mathrm{M}$ ). The Ringer's solution contained (in mM): $126 \mathrm{NaCl}, 26 \mathrm{NaHCO}_{3}, 3 \mathrm{KCl}, 1.2 \mathrm{KH}_{2} \mathrm{PO}_{4}, 1.6$ $\mathrm{MgSO}_{4}, 2 \mathrm{CaCl}_{2}, 5$ HEPES, and 15 dextrose.

\section{Histology}

After completion of the recording sessions, the injection pipette was filled with alcian blue solution $(10 \mathrm{mg} / \mathrm{ml}$ in saline), and a small amount $(\sim 0.3 \mu \mathrm{l})$ was injected to mark the tip position. The animal was then perfused intracardially with $0.9 \%$ saline followed by $10 \%$ formalin. The dissected brain was immersed in $10 \%$ formalin overnight followed by $30 \%$ sucrose formalin for at least $2 \mathrm{~d}$. Parasagittal or coronal $60 \mu \mathrm{m}$ sections were cut with a freezing microtome and counterstained with cresyl violet.

\section{Multichannel recording system}

The basic multichannel recording system that was used has been described previously (Sugihara et al., 1993). Briefly, CS signals from all recording channels were converted to transistor-transistor-logic pulses, stored on videocassette recorder tape, and captured onto a Pentium II personal computer (Dell) with a 1 msec intersampling period per channel using a digital input-output board (National Instruments). Data analyses were performed using custom-made programs written in Fortran or within the IGOR (WaveMetrics) programming environment.

\section{Data analysis}

Calculation of correlation coefficients was performed according to previously developed methods (Gerstein and Kiang, 1960; Sasaki et al., 1989). The spike train of a cell is represented by the function $X(i)$, where $i$ represents the time step $(i=1,2, \ldots, N)$ and $X(i)=1$ if the onset of a CS occurred in the $i$ th time step and otherwise $X(i)=0 . Y(i)$ is defined the same as $X(i)$ but represents the spike train of a second cell. The correlation coefficient $C(t)$ is then calculated using the standard formula for determining a correlation coefficient:

$$
C(t)=\sum_{i=1}^{N} V(i)^{*} W(i-t) / \sqrt{\sum_{i=1}^{N} V(i)^{2} \sum_{i=1}^{N} W(i)^{2}},
$$

where:

$$
\begin{aligned}
& V(i)=X(i)-\sum_{i=1}^{N} X(i) / N, \\
& W(i)=Y(i)-\sum_{i=1}^{N} Y(i) / N,
\end{aligned}
$$

and $t$ represents the time lag between compared times of the spike trains. Analysis of oscillatory properties. Autocorrelation histograms were constructed for CS spike trains of single Purkinje cells with time bins of 5 or $10 \mathrm{msec}$. The oscillation frequency was taken as the reciprocal of the latency of the first peak in the autocorrelogram, whereas the strength of the oscillation was quantified using several measures, including the number of peaks in the autocorrelogram, the height of the first peak with respect to the total number of firings, and a rhythm index (RI). The RI used here is similar to that used by Sugihara et al. (1995). First, the average level of the autocorrelogram between 50 and $1000 \mathrm{msec}$ was calculated. Next, the SD of activity about the mean level was measured at time lags of $2000-2500 \mathrm{msec}$ at which oscillatory activity was largely absent and random fluctuations dominated the autocorrelograms. To be recognized, peaks and valleys in the autocorrelogram had to be greater than \pm 1 SD from the average level of the histogram from 50 to 1000 msec, or the difference between a successive peak and valley had to exceed 2 SDs. Furthermore, the successive peaks had to occur at intervals equal to the latency of the first peak $\pm 10 \mathrm{msec}$, whereas the valley after a peak had to occur at a latency from the preceding peak that was equal to half the latency of the first peak $\pm 10 \mathrm{msec}$. The search for peaks was terminated with the first failure to find a significant peak. The RI was then defined by the following formula:

$$
\mathrm{RI}=a_{1}+b_{1}+a_{2}+b_{2}+\ldots,
$$

in which $a_{i}$ and $b_{i}$ are equal to the absolute values of the autocorrelation coefficients of the significant peaks $\left(a_{i}\right)$ and valleys $\left(b_{i}\right)$ in the autocorrelogram. These coefficients are calculated using the formula for $C(t)$ with 
$X(i)=Y(i)$ and $t$ equal to the latencies of the peaks $a_{i}$ and troughs $b_{i}$. The greater the RI the tighter or stronger was the oscillatory activity. In the autocorrelograms that had no recognizable peaks and valleys, a value of zero was given to the RI. In these cases, or when the RI was $<0.01$, the autocorrelation was regarded as nonoscillatory, and the oscillation frequency was not determined.

Analysis of synchrony. The degree of synchronous CS activity was measured by calculating the zero-time cross-correlation coefficient $C(0)$, using the equation for $C(t)$ with $t=0$. As a second measure of synchrony, the number of synchronous spikes between two cells was expressed as a percentage of the total number of spikes in the reference cell. In both methods, the time step $i$ used for the synchrony analysis was $1 \mathrm{msec}$, and thus synchronous activity is defined as spikes initiating within $1 \mathrm{msec}$ of each other. It should also be noted that although the cross-correlation coefficients of cell pairs displaying synchronized CS activity are small in absolute terms [with $C(0)$ mostly ranging from 0.01 to 0.30 ], these values are statistically highly significant, because they are one to two orders of magnitude greater than that expected by chance (Sugihara et al., 1993) and have a nonrandom spatial distribution. Furthermore, the possibility of spurious correlations because of the rhythmic nature of CS activity and the finiteness of our data set is unlikely, because calculation of cross-correlation coefficients between cell pairs in which the interspike intervals from one of the spike trains have been randomized yields correlations one to two orders of magnitude smaller than those observed here (Lang et al., 1996).

\section{Estimation of ketamine concentration in the brain}

Interpretation of the present results rests in part on the assumption that NMDA-mediated glutamatergic neurotransmission within the IO was absent. Several lines of evidence (described in Results) indicate that this was the case. One of these lines is that the anesthetic ketamine is an NMDA antagonist (Ebert et al., 1997). To determine whether during the experiment the ketamine levels in the brain were actually high enough to ensure blockade of NMDA receptors (at least 20-100 $\mu \mathrm{M}$ ) (Ebert et al., 1997), the concentration of ketamine was estimated as follows.

After an initial intraperitoneal injection of ketamine, the anesthetic level was maintained in most experiments by bolus intravenous injections of the anesthetics. These bolus injections resulted in $1.5 \mathrm{mg}$ of ketamine entering the blood every $30 \mathrm{~min}$. The amount of ketamine in the blood at time $t$ can then be estimated from the following equation:

$$
X_{t}=X_{t-1} e^{-k_{s} \Delta t}+1.5 e^{-k_{f} \Delta t},
$$

where $\mathrm{X}_{\mathrm{t}-1}$ is the amount of ketamine in the blood at the time of the previous injection, $\Delta t=30 \mathrm{~min}$, and $k_{f}$ and $k_{s}$ are the initial and terminal time constants, respectively, for the disappearance of ketamine from the plasma. Ketamine concentration in the blood after intravenous injection initially falls rapidly with a half-life of $t_{1 / 2}=17 \mathrm{~min}$, giving a $k_{f}$ of 0.039 , and then falls more slowly with a $t_{1 / 2}=186 \mathrm{~min}$ and a $k_{s}=0.0038$ (Clements and Nimmo, 1981). To obtain the minimum amount of ketamine at steady-state, we can subtract $X_{t-1}$ from both sides of the equation and set the difference $X_{t}-X_{t-1}=0$ :

$$
0=X_{t}-X_{t-1}=X_{t-1}\left(e^{-k_{s} \Delta t}-1\right)+1.5 e^{-k_{f} \Delta t} .
$$

Solving for $X$ with $\Delta t=30$ min gives:

$$
X_{\text {steady-state }}=1.5 e^{-30 k_{f}} /\left(1-e^{-30 k_{s}}\right) .
$$

Using the given values of $k_{f}$ and $k_{s}$ yields $X_{\text {steady-state }}=4.32 \mathrm{mg}$. Female Sprague Dawley rats contain $\sim 63 \mathrm{ml}$ of blood $/ \mathrm{kg}$ [Schalm et al. (1975), their Table 1]. Therefore, $250 \mathrm{gm}$ rats will contain $15.75 \mathrm{ml}$ of blood, giving a steady-state ketamine (molecular weight $=274$ ) blood concentration of $1001 \mu \mathrm{M}$.

In one experiment, intravenous anesthesia was given in a continuous manner using a microdialysis pump (CMA-102; CMA MicroDialysis). Ketamine dissolved in saline was injected at a constant rate of $51 \mu \mathrm{g} / \mathrm{min}$, so that the amount $(1.53 \mathrm{mg})$ of ketamine delivered in $30 \mathrm{~min}$ was similar to that delivered by the bolus injections. Assuming that the fast decay decreases the effective amount of ketamine delivered to $15.83 \mu \mathrm{g} / \mathrm{min}$ $\left(=51 \mathrm{e}^{-0.039 * 30}\right)$, the steady-state amount of ketamine in the blood may be estimated by:

$$
\frac{\mathrm{d} x}{\mathrm{~d} t}=15.83-k_{s} X=0
$$

Using the values of the time constants above, the blood concentration of ketamine would be $1013 \mu \mathrm{M}$, similar to the concentrations achieved by the bolus injections and constant in value through time.

Measurements of relative blood and brain concentrations of ketamine in Sprague Dawley rats after intravenous injections show that brain concentrations are six- to sevenfold higher than those of blood (Cohen et al., 1973). Thus, the concentrations of ketamine in the brain in the present experiments are estimated to have been in the range of $6-8 \mathrm{~mm}$.

\section{RESULTS}

The present experiments investigated the role of excitatory glutamatergic input to the IO in modulating the firing rate, rhythmicity, and synchronization of olivocerebellar activity by using simultaneous recordings of CS activity and performing microinjections of non-NMDA glutamate blockers into the IO. In total, multiple electrode recordings of CS activity were obtained from 236 crus $2 \mathrm{a}$ Purkinje cells in eight Sprague Dawley rats (range, 22-36 cells/ animal). However, 21 (9\%) of these cells were "lost" during the recording sessions and were excluded from the analyses. The CS activity of the remaining 215 cells formed the database for the results described below. These CSs displayed a characteristic multipeaked waveform (Fig. $1 A$, inset, Spontaneous) and under control conditions had an average firing rate of $1.02 \pm 0.04 \mathrm{~Hz}$ (mean \pm $\mathrm{SE}$ ), typical for CS activity. Intraolivary injections of Ringer's solution were performed in three animals ( $n=79$ cells), CNQX injections were performed in four animals ( $n=98$ cells), and NBQX injections were made in three animals $(n=93$ cells). The results of CNQX and NBQX injections were virtually identical and were pooled for analysis purposes.

\section{Glutamate antagonists block CS responses evoked by motor cortex or perioral stimulation}

Stimulation of the vibrissal region of the contralateral motor cortex evoked CS activity in crus 2a Purkinje cells. The CS responses typically occurred at latencies from 13 to $25 \mathrm{msec}$ and were sometimes preceded by a triphasic field potential. In the example shown in Figure 1A, Control, the stimulus artifact was followed by an initial triphasic field potential at a latency of $\sim 7$ msec (indicated by *) and a CS response (indicated by **) at a latency of $\sim 15 \mathrm{msec}$. The short latency of the initial field precludes its being related to climbing fiber activity. This fact is demonstrated by the histograms in Figure 1, $C$ and $D$, which plot the latencies of the onsets of simultaneously recorded responses to motor cortical stimuli ( 300 shocks at $0.5 \mathrm{~Hz}$ ) that were evoked in the cerebellum (Fig. 1C, Control) and IO (Fig. 1D). The histogram of evoked cerebellar activity under control conditions is bimodal, with the first peak from 7 to $12 \mathrm{msec}$ and the second one from 15 to $25 \mathrm{msec}$ (Fig. $1 C$ ). These peaks correspond in time to the evoked field potentials and CSs, respectively. In contrast, the histogram of IO responses is unimodal, with responses primarily restricted to a range of $10-22 \mathrm{msec}$ (Fig. 1D). Because of the 4-5 msec conduction time from the IO to the cerebellar cortex in rat (Sugihara et al., 1993), the expected latency of CS activity in the cerebellar cortex is $14-27 \mathrm{msec}$, closely matching the second peak of the control cerebellar histogram. The initial peak in the control histogram (Fig. $1 C$ ), being coincident with the earliest part of the response in the IO, cannot be caused by olivocerebellar activity. Instead it is presumably caused by the activation of the mossy fiber-parallel fiber system. 

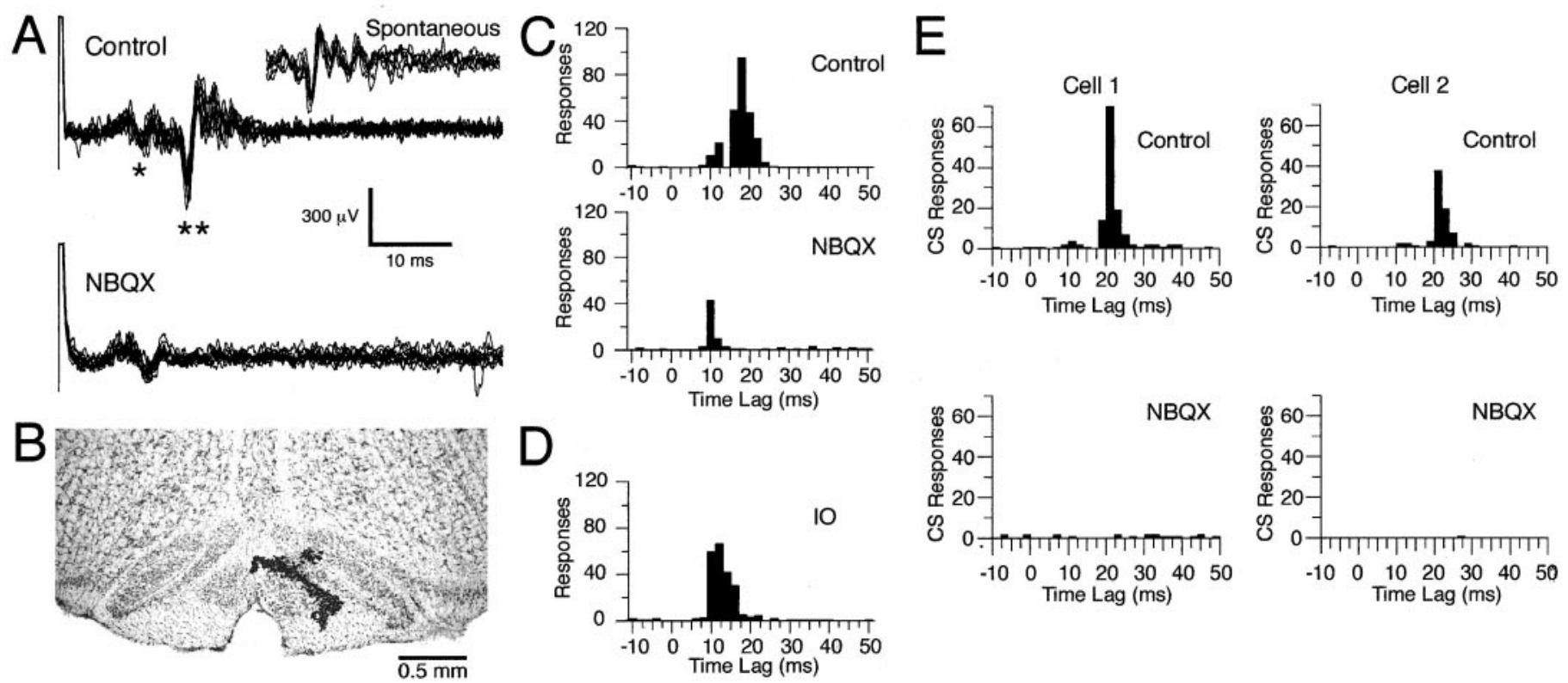

Figure 1. Block of stimulus-evoked olivocerebellar activity by intraolivary injection of glutamate antagonists. $A$, Extracellular recording of Purkinje cell responses to motor cortical stimuli. In the control condition, motor cortical stimuli ( $1.5 \mathrm{~mA}$ pulse of $200 \mu$ sec $)$ evoked an initial triphasic field potential (*) followed by a CS response (**). After injection of NBQX, the CS response is abolished. Responses to 10 stimuli are overlapped in each condition. Inset, Seven overlapped spontaneous CSs demonstrating the similarity in duration and waveform to the evoked CS activity. $B$, Contrast-enhanced $60-\mu \mathrm{m}$-thick coronal section of brainstem counterstained with cresyl violet showing an injection site in the rostral medial portion of the IO. The injection site was marked by a pressure injection of alcian blue dye at the conclusion of the experiment (dark spots within the IO). $C$, Peristimulus histograms of Purkinje cell activity (same cell shown in $A$ ) evoked by motor cortical stimulation. $D$, Peristimulus histogram of multiunit recording of IO activity from the same control condition shown in $C$. Histograms in $C$ and $D$ were compiled from responses to 300 stimuli. $E$, Peristimulus histograms showing CS responses of two cells to brief jabs applied to the upper lip with a stylus before (Control) and after $(N B Q X)$ intraolivary injection of NBQX. Histograms were generated from the CS responses during 600 trials (intertrial period was $1 \mathrm{sec}$ ). Bin size equals $2 \mathrm{msec}$.

It should be noted that because a simple threshold was used to detect responses it is possible that the early and late peaks may not be pure field potential and CS responses, respectively. However, several considerations indicate that any cross-contamination was minimal. First, the conduction times between the motor cortex, IO, and cerebellum described above indicate that evoked CS activity cannot occur at a short enough latency to contribute to the early peak of the histograms; nevertheless, some "spontaneous" CSs could occur by chance at those times. However, because of the typical $1 \mathrm{~Hz}$ average firing rate of CS activity and because the peristimulus histograms were compiled from 300 trials, the contribution of CS activity to each $2 \mathrm{msec}$ bin would be expected to be $\sim 0.6$ responses. The early peaks of the histograms are 20-40 responses; therefore the contamination represents an error of $1-2 \%$. The contamination of the second peak by field potentials was also minimal for several reasons. It can be seen from the voltage records in Figure $1 A$ that there was little variation in the latency of the early field and that it terminated before the earliest time at which CSs occurred. The identification of the first and second histogram peaks with the field potentials and CS responses, respectively, is further reinforced by the differential effect that the toxin injections had on the two peaks as shown in Figure $1 C$ and as described below.

Injection of the glutamate receptor antagonists CNQX or NBQX into the rostral medial region of the IO (Fig. 1B), which gives rise to the projection to crus 2a (Llinás and Sasaki, 1989), led to the selective disappearance of evoked CS responses as shown by the extracellular recordings (Fig. $1 A, N B Q X$ ) and by the loss of the second peak in the peristimulus histogram (Fig. $1 C$, $N B Q X)$. Note that the continued presence of the early field potential indicates that the stimulation continued to activate the motor cortex effectively. The results indicate that postsynaptic responses at the final synapse of descending motor pathways to the IO are mediated by AMPA/kainate-type glutamate receptors, although a contribution from NMDA receptors cannot be excluded because of the effects of ketamine anesthesia on these receptors.

Mechanical stimulation of the perioral region is known to evoke CSs in crus 2a Purkinje cells (Llinás and Sasaki, 1989). In agreement with previous reports, tactile stimuli to the perioral region evoked CSs at latencies of 20-35 msec in crus 2a Purkinje cells (Fig. 1E, Control). Injection of NBQX to the IO blocked CS responses evoked by tactile stimulation (Fig. $1 E$ ). Thus, the final synapse of this IO afferent pathway also uses AMPA/kainatetype glutamate receptors.

In addition to demonstrating that major excitatory pathways to the IO use glutamate receptors, the loss of evoked CS responses was used as an independent measure of the efficacy of the injection in blocking excitatory input in five of the seven experiments in which intraolivary injections of CNQX or NBQX were performed ( $n=138$ cells). In the remaining two experiments, evoked CS responses were not elicited, but the injection sites were histologically confirmed to be within the IO, and the injections produced changes in spontaneous $\mathrm{CS}$ activity that were identical to those in the experiments in which the loss of evoked CS activity was measured. Although the loss of evoked CS responses clearly demonstrates that glutamatergic activity was blocked to the region of the IO that projects to crus $2 \mathrm{a}$, several additional considerations support the idea that AMPA receptor-mediated activity was blocked throughout the IO. First, the injection pipette was positioned in the IO using stereotactic and electrophysiological criteria, and its location was verified histologically in 


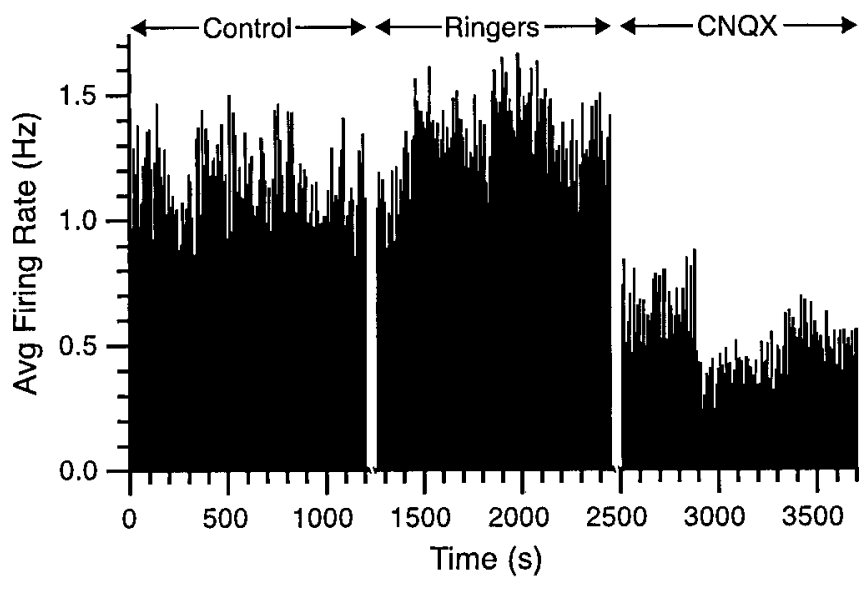

Figure 2. Spontaneous CS activity decreases with intraolivary CNQX injections. The rate meter was calculated from an experiment in which 29 cells were simultaneously recorded. The rate meter shows the single-cell firing rate averaged over the 29 cells for successive $10 \mathrm{sec}$ intervals during three 20 min recording conditions (Control, Ringers, CNQX). Time is continuous within each recording condition but not between conditions (i.e., there was a 10-15 min period between each recording condition to exchange the solution of the injection pipette). Avg, Average.

each experiment (Fig. $1 B$ ). Second, the concentration of CNQX and NBQX used was 10-fold greater than that needed to block AMPA receptors in vitro and was the same as that that blocked glutamatergic miniature postsynaptic potentials in pyramidal neurons for a 3-mm-diameter region of cortex when injected in a similar manner (Paré et al., 1997). Thus, because of this effective diameter, the pipette tip being located within the IO, and the size of the IO in rat $(2.5 \times 1.8 \times 0.6 \mathrm{~mm})($ Paxinos and Watson, 1998), a complete block of AMPA receptors throughout the IO should have been achieved.

Furthermore, in the present experiments the block of AMPA receptors by $\mathrm{CNQX}$ or $\mathrm{NBQX}$ was taken as equivalent to blocking glutamatergic input, despite the presence of NMDA receptors in the IO (Petralia et al., 1994). Several factors indicate that, under the present experimental conditions, NMDA receptors are not activated and that it is valid to equate blocking AMPA receptors to blocking glutamatergic input. First, evoked CS responses after motor cortical or facial stimulation were lost after injection of NBQX or CNQX (Fig. $1 A$ ), indicating that blocking AMPA receptors was sufficient to block the excitatory action of these two glutamatergic afferent pathways and that NMDAmediated excitation did not occur in the absence of the initial depolarization generated by AMPA receptor-mediated currents. This result is easily explained by the well known voltage dependence of most NMDA responses because of $\mathrm{Mg}^{+2}$ block of the channel. It is conceivable that different olivary afferent pathways use distinct glutamate receptor types and that the two glutamatergic pathways tested here do not activate NMDA responses; however, there is no evidence of such parcellation of glutamate receptor subtype by IO afferents, and the voltage dependence of such channels would still argue against their activation after AMPA blockade. A second line of evidence further indicates that NMDA receptors were blocked in the current experiments; namely, the anesthetic ketamine, a noncompetitive blocker of NMDA receptors (Martin and Lodge, 1985), was present in millimolar concentrations in the brain (see Materials and Methods for estimation of ketamine concentration), which is several orders of magnitude greater than the $20-100 \mu \mathrm{M}$ concentrations needed to block NMDA receptors (Ebert et al., 1997). Finally it should be noted that use of ketamine prevents definitive determination of the role of NMDA-mediated neurotransmission in shaping spontaneous CS activity; however, a previous study comparing spontaneous CS activity patterns in ketamine-xylazineanesthetized and awake rats found that they were very similar in these two conditions (Lang et al., 1999).

\section{Spontaneous CS activity remains after intraolivary injection of CNQX or NBQX}

To determine whether block of glutamatergic inputs to the IO affected spontaneous CS activity, the average CS firing rate was calculated under control conditions and after intraolivary injections of CNQX $(200 \mu \mathrm{M})$ or NBQX $(200 \mu \mathrm{M})$. In seven experiments in which intraolivary injections of the antagonists were performed, the average CS firing rate during the 20-min-duration control period was $1.05 \pm 0.04 \mathrm{~Hz}$ ( $n=191$ cells). During intraolivary injection of glutamate receptor blockers, the average CS firing rate fell to $0.53 \pm 0.04 \mathrm{~Hz}$, significantly less than control levels $(t=9.09 ; p<0.001 ; n=191$ cells; two-sided $t$ test $)$. Note that the activity from 20 electrodes was lost, and 5 of the losses were caused by electrode malfunction. The reason for the silencing of CS activity from the remaining 15 (9.5\%) electrodes was uncertain, possibly being caused by recording instability, damage to the IO produced by the injection, or the effect of NBQX or CNQX. During the Ringer's solution injections only 1-2\% of the cells were lost, suggesting that IO damage may account for some of the loss but leaving open the possibility that a small proportion of IO neurons $(<8 \%)$ may be silenced in the absence of excitatory drive. Because of this uncertainty, the lost cells were excluded from the firing rate and all subsequent calculations; thus, the true CS firing rate after block of glutamatergic input is probably slightly lower than $0.53 \mathrm{~Hz}$ (including all 15 lost cells with a firing rate of $0 \mathrm{~Hz}$ only drops the average rate to $0.49 \mathrm{~Hz}$ ). Nevertheless, it was clear that in the large majority of cells, spontaneous CS activity, although reduced, was not eliminated.

The $\sim 50 \%$ decrease in average firing rate after glutamate receptor blocker injections can be contrasted with the lack of effect of intraolivary Ringer's solution injections on average CS firing rate. In three experiments in which Ringer's solution injections were performed, the average CS firing rate during the control period was $1.12 \pm 0.07 \mathrm{~Hz}$ ( $n=79$ cells), whereas after injection of Ringer's solution the rate was virtually unchanged $(1.14 \pm 0.07 \mathrm{~Hz} ; n=79$ cells $)$. In two of these experiments, the Ringer's solution injection was followed by injection of CNQX. The average firing rates for the three conditions in these two experiments were as follows: control, $1.25 \pm 0.09 \mathrm{~Hz}(n=53)$; Ringer's solution, $1.24 \pm 0.10 \mathrm{~Hz}(n=53)$; and CNQX, $0.74 \pm$ $0.08(n=53)$. The difference between the firing rates in the control and Ringer's solution conditions was not significant $(t=$ $0.261 ; p>0.25)$, whereas the difference between the CNQX condition and either control or Ringer's solution was significant (CNQX vs control, $t=4.308 ; p<0.001$; CNQX vs Ringer's solution, $t=3.939 ; p<0.001)$.

The effects of the drug injections on firing rate were sustained throughout the recording sessions as can be seen in the rate meters from one typical experiment in which CS activity was simultaneously recorded from 29 Purkinje cells (Fig. 2). Rate meters from control and Ringer's solution periods showed similar levels of activity, whereas during the injection of CNQX, the CS firing rate dropped to approximately half that of the first two conditions. 


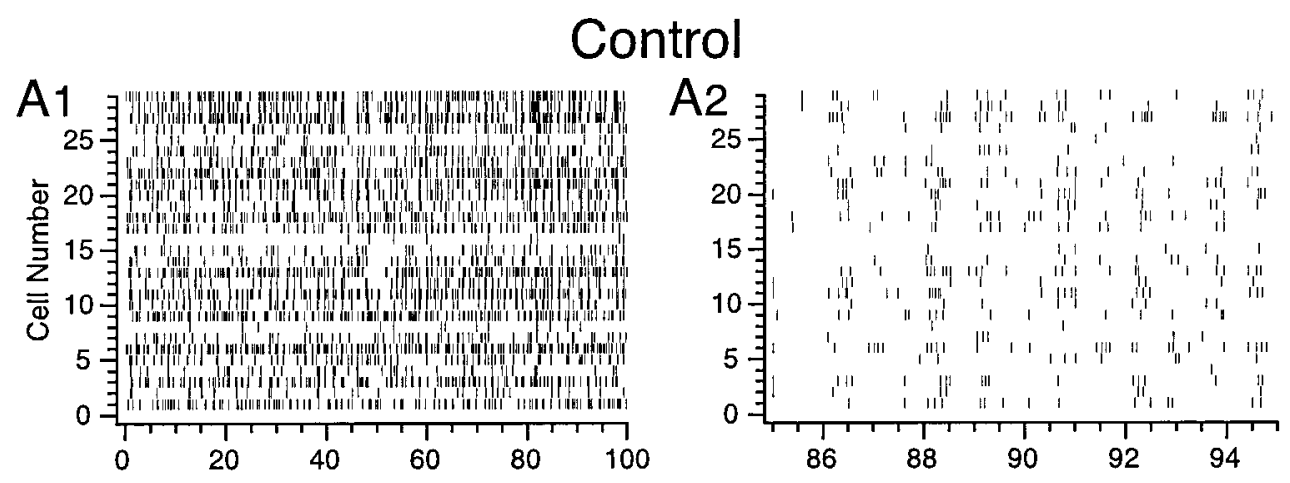

Figure 3. Raster displays of CS activity during control $(A 1, A 2)$ and after intraolivary injection of CNQX $(B 1, B 2)$. In this experiment, $C S$ activity was recorded from 29 Purkinje cells simultaneously. Each horizontal row of tick marks represents the CS activity from a single Purkinje cell. Note the decrease in overall activity induced by the injection and the change in the pattern of activity $(A$ vs $B)$. The details of the shift in firing pattern induced by the CNQX injection are illustrated by rasters with an expanded time scale $(A 2, B 2)$.

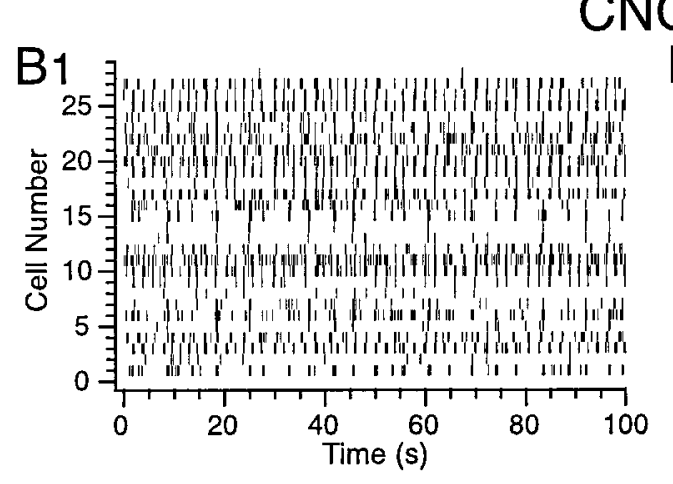

CNQX

\section{Blocking excitatory input to the 10 increases the rhythmicity of complex spike activity}

Injection of CNQX or NBQX not only decreased the average CS firing rate but also dramatically changed its temporal organization. This can be seen by comparing the raster displays of CS activity in the control (Fig. $3 A$ ) and during injection of CNQX to the IO (Fig. 3B). In the control period, there were periods of repetitive firing; however, there were also many solitary CSs present. In contrast, during the injection of CNQX, CS activity consisted almost exclusively of bursts of rhythmic activity separated by periods of near silence.

The effect of glutamate receptor blocker injections on CS rhythmicity was investigated further by constructing autocorrelograms of CS activity. Typical examples of autocorrelograms from two cells are shown in Figure 4. The autocorrelograms of CS activity during the control period displayed one to two peaks at $\sim 100 \mathrm{msec}$ intervals, indicating the presence of the usual $\sim 10 \mathrm{~Hz}$ rhythmicity of CS activity (Fig. 4A). The changes in CS rhythmicity after injection of NBQX were immediately apparent in the autocorrelograms. Compared with control, the peaks of the autocorrelograms increased in number and height and became narrower (Fig. 4B). The baseline level of the correlogram also decreased. Such changes, indicative of an increased rhythmicity coupled with a decreased average firing rate, were produced by the antagonist injections in every experiment.

To quantify the changes produced by the injection, three measures of rhythmicity were used: (1) number of significant peaks, (2) height of the primary peak expressed as a percentage of the total number of spikes, and (3) the RI. By the use of any of these measures, CS rhythmicity after block of intraolivary glutamatergic receptors increased significantly $(p<0.001)$. The average number of peaks in the autocorrelograms increased from $1.69 \pm$ 0.07 in control to $2.74 \pm 0.10(t=8.32 ; n=172)$ during injection of CNQX or NBQX, the height of the primary peak increased from $4.22 \pm 0.19 \%$ to $11.93 \pm 0.82 \%(t=9.11 ; n=172)$, and the RI increased fourfold from $0.0498 \pm 0.0030$ to $0.2039 \pm 0.0164$ $(t=9.25 ; n=172)$. The increase in CS rhythmicity indicated by these measures occurred in the vast majority of recorded neurons, with $87 \%$ of the cells having an increased RI during the injections as compared with control.

In addition to increasing CS rhythmicity, blocking glutamate receptors in the IO produced a shift in the CS oscillation frequency. In control, the average latency to the first peak in the autocorrelogram was $99.11 \mathrm{msec}(n=161)$, corresponding to an oscillation frequency of $10.09 \pm 0.17 \mathrm{~Hz}(n=161)$, whereas during injection of NBQX or CNQX a significantly $(t=5.88 ; p<$ $0.001)$ faster oscillation frequency of $12.21 \pm 0.32 \mathrm{~Hz}(n=168)$ was observed, which corresponded to a first-peak latency of 81.90 msec. Examples of this shift can be observed in the autocorrelograms (Fig. $4 A$ vs $B$ ) and fast Fourier transforms (FFTs) (Fig. $4 C$ ). In these cells, the oscillation frequencies shifted from 9.4 and $10.6 \mathrm{~Hz}$ in control to 15.6 and $15.2 \mathrm{~Hz}$ after block of glutamate receptors.

To test whether any of these changes in CS rhythmicity could be ascribed to the injection process itself, intraolivary injections of Ringer's solution were performed ( $n=3$ experiments, 76 cells). These injections produced no significant increases in CS rhythmicity on any of the measures used. In fact, Ringer's solution injections actually tended to produce slight decreases in rhythmicity. In two of these animals ( $n=52$ cells) the Ringer's solution injection was followed by injection of CNQX, which produced the typical increase in CS rhythmicity observed with injection of NBQX or CNQX. A comparison of the different measures of CS rhythmicity in the three conditions is shown in Figure $5 A$, and examples of autocorrelograms from two typical cells under the three conditions are shown in Figure $5 B$. The results indicate that Ringer's solution injections had little to no effect on CS rhythmicity in comparison with the significant 

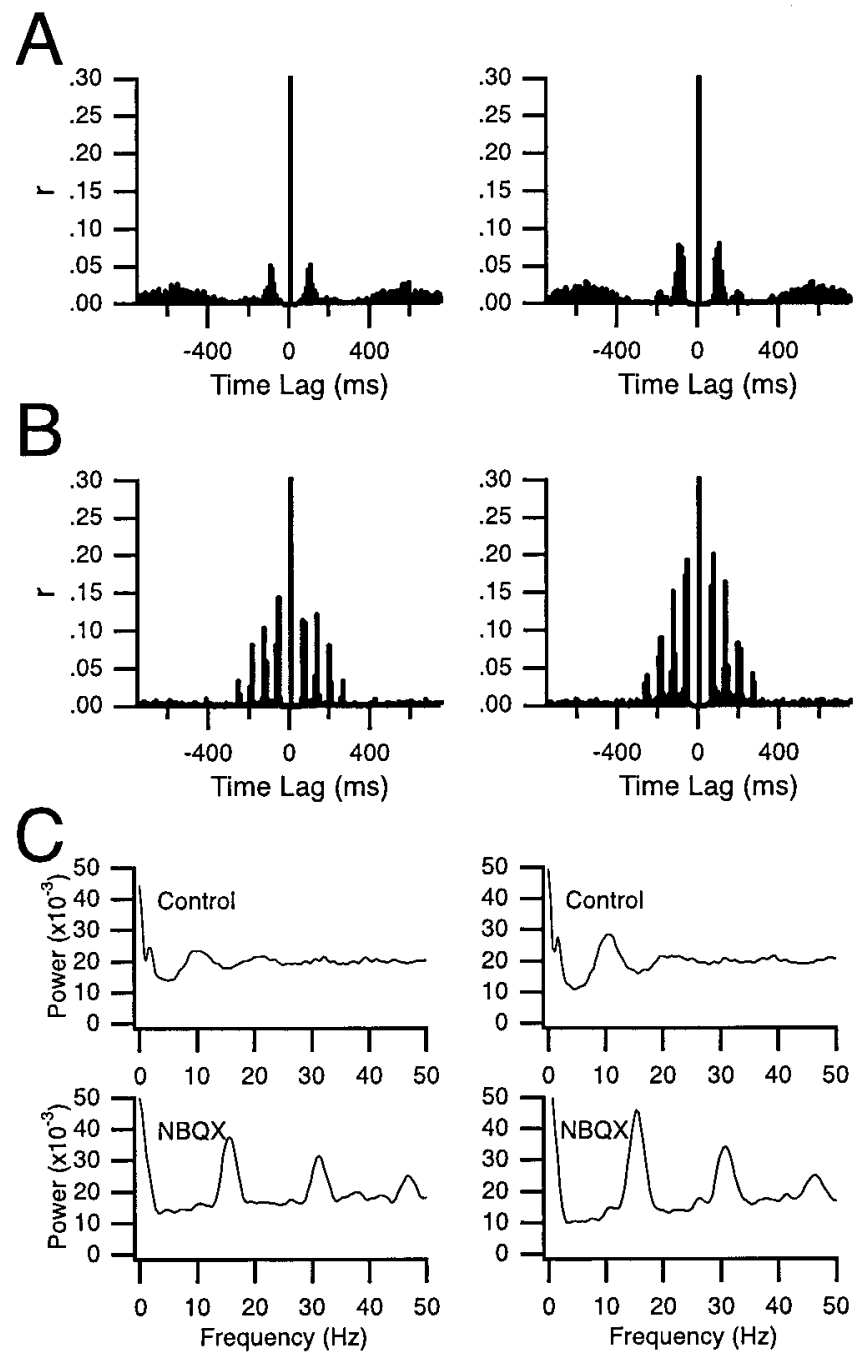

Figure 4. Increase in CS rhythmicity after intraolivary NBQX injection. $A, B$, Normalized autocorrelograms of the CS activity recorded from two Purkinje cells during a $20 \mathrm{~min}$ control period $(A)$ and during a $20 \mathrm{~min}$ period after block of glutamatergic input to the inferior olive by NBQX (B). The central peaks are truncated in $A$ and $B$. $C$, FFTs of the autocorrelograms shown in $A$ (top) and $B$ (bottom) illustrating the shift in oscillation frequency from $10 \mathrm{~Hz}$ in control to $15 \mathrm{~Hz}$ after injection of NBQX. Each column shows histograms and FFTs from one cell.

changes produced by the antagonist injections, indicating that block of IO glutamate receptors was the cause of the changes in CS rhythmicity.

\section{Distinct oscillatory and nonoscillatory firing modes for complex spike activity}

Examination of the raster displays revealed that under control conditions CSs may occur either as a series of repetitive spikes with $\sim 100 \mathrm{msec}$ interspike intervals or as isolated spikes (Fig. $3 A 2$ ), suggesting that the olivocerebellar system may have two distinct functional states, one state characterized by rhythmic activity with a preferred oscillation frequency of $\sim 10 \mathrm{~Hz}$ and a second state in which random firing predominates. Interestingly, after intraolivary injections of CNQX or NBQX, primarily the repetitive CS firing patterns remained (Fig. 3B2), suggesting that these two patterns may correspond to whether olivocerebellar activity is being generated by intrinsic oscillatory mechanisms or in response to excitatory afferent activity. This issue was explored by generating interspike interval scatter plots in which $x-y$ pairs were formed by taking successive interspike intervals of CS activity $\left[x_{i}, x_{(i-1)}\right]$. Interval plots for the CS activity from three cells, exemplifying the typical patterns that were observed, are shown in Figure 6. Under control conditions, the plots of most cells $(\sim 80 \%)$ displayed four major areas of high density that were separated from each other by regions containing few points that represent infrequent firing patterns (Fig. 6, left column).

Points within the high-density region in the lower left corner (Fig. 6, left column) result from three successive spikes with interspike intervals of $60-110 \mathrm{msec}$. This region reflects the presence of 9-16 Hz oscillatory CS activity that was sustained for at least three cycles and demonstrates that the secondary peaks in the CS autocorrelograms were not simply the result of doublets at half the typical oscillation frequency. Thus, IO neurons are capable of sustained suprathreshold oscillatory activity and not just doublets. With regard to the regularity of the oscillation, it is important to note that the lower left high-density region was circularly shaped for all cells, indicating that the oscillation frequency may vary within a limited range during individual repetitive firing sequences (an elliptic shape, with its major axis aligned along the $45^{\circ}$ diagonal, would have indicated a fixed oscillation frequency during any one sequence).

The points comprising the high-density region of the upper right corner (Fig. 6, left column) result from three spikes at relatively long interspike intervals on the order of $1 \mathrm{sec}$. Both the circular shape of this region and its large diameter $(\sim 40$ times that of the lower left corner region) indicate a relatively random firing pattern with an average rate of 1-2 Hz.

The two remaining high-density zones can be thought of as transitional zones between the first two zones. That is, the firing patterns of each consist of a pair of spikes with an $\sim 100 \mathrm{msec}$ interval either followed (Fig. 6, left column, lower right) or preceded (upper left) by a long interspike interval. In summary, the olivocerebellar system appears to have two functional states characterized by two distinct firing patterns: oscillatory (at $\sim 10 \mathrm{~Hz}$ ) and random (at $1-2 \mathrm{~Hz}$ ).

Intraolivary injections of CNQX or NBQX dramatically changed the interspike interval plots of most cells (Fig. 6, right column). In all cases, there were fewer points for an identicallength recording period, reflecting the lower average firing rates after the injection. However, the major change was in the differentially greater loss of points from the upper right corner region, reflecting a selective decrease in the random activity pattern. In some cases, this region was virtually eliminated (Fig. 6B, compare left, right columns). Moreover, the points comprising the oscillatory region became more tightly clustered and were centered on the inner boundary that this region displayed under control conditions. After the block of glutamatergic inputs, the oscillatory region of $\sim 17 \%$ of the cells contained several subclusters (Fig. $6 C$, right column), indicative of specific preferred oscillatory frequencies. This phenomenon probably reflects the discrete jumps in the duration of the calcium spike of IO neurons (Crill, 1970; Llinás and Yarom, 1986). The subclustering was not clearly observed in the plots from CS activity under control conditions.

\section{Complex spike synchrony during CNQX or NBQX injections into the inferior olive}

Complex spike synchrony has been hypothesized to be caused by the electrotonic coupling of IO neurons via gap junctions (Llinás et al., 1974). However, it is also possible that synchronous CS activity is the result of synchronous excitatory input to the IO. To 

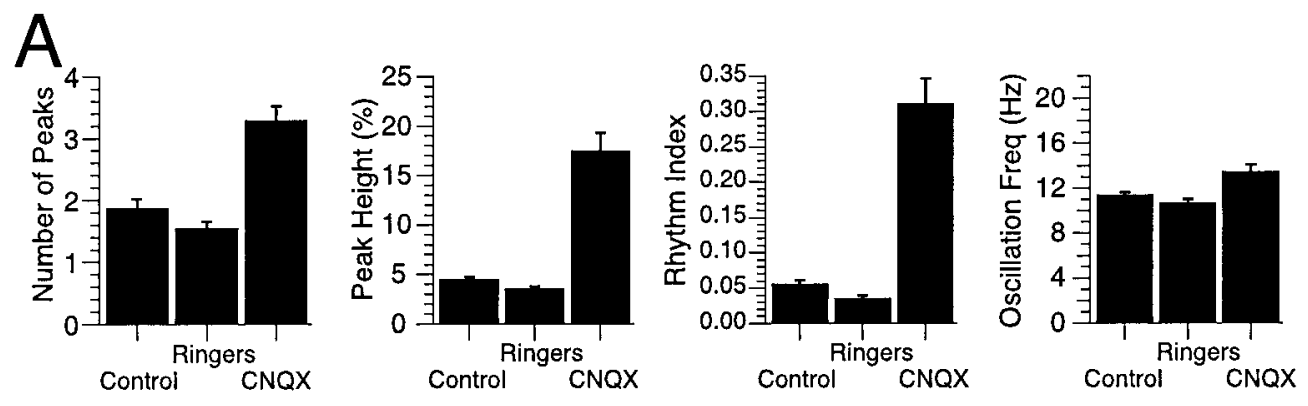

Figure 5. Injections of CNQX but not Ringer's solution alter CS rhythmicity. $A$, The characteristics of CS rhythmicity were quantified using several measures: number of peaks, peak height, rhythm index, and oscillation frequency. The histograms compare the mean value \pm SEM of these measures in control and after injection of Ringer's solution and CNQX in the same animals. Histograms are based on CS activity recorded from 52 Purkinje cells in two animals. $B$, Autocorrelograms of CS activity from two Purkinje cells recorded under all three conditions illustrate the similarity of the CS activity during injection of Ringer's solution to that in control conditions and the dramatic change induced by CNQX injections. Note that the central peaks are truncated. All recording sessions (Control, Ringers, $C N Q X)$ were $20 \mathrm{~min}$ in duration. Freq, Frequency.
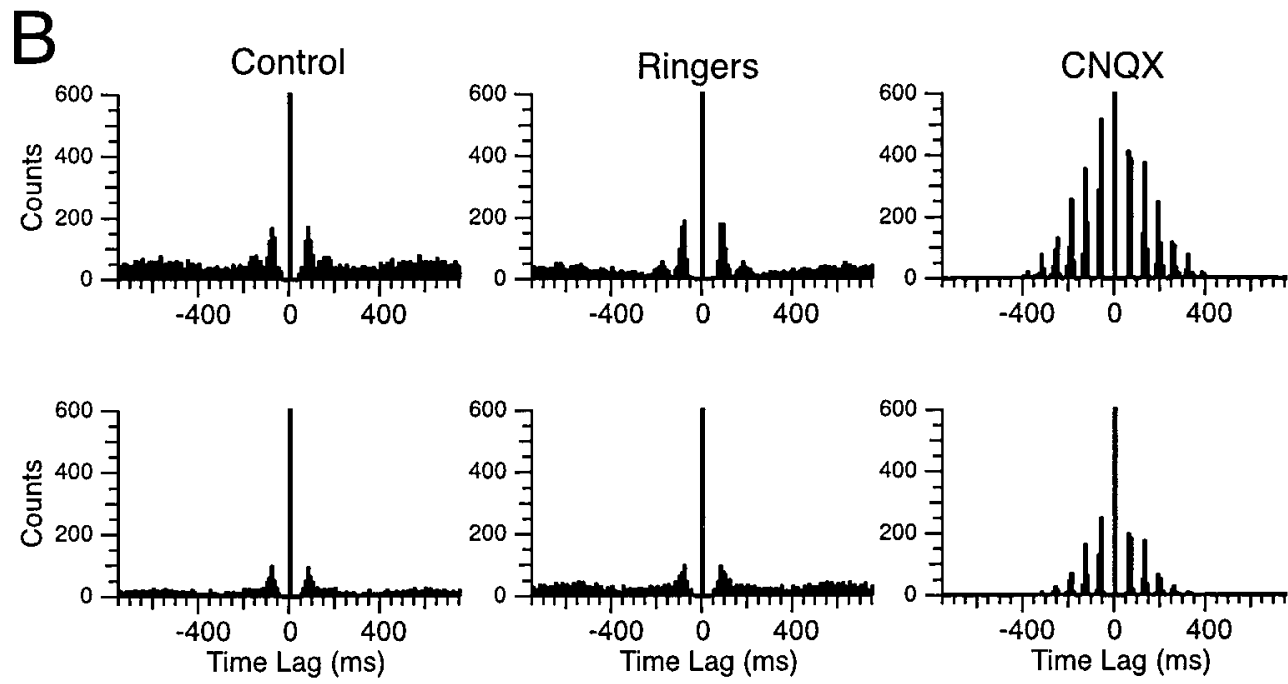

investigate this possibility, the effect of intraolivary injections of CNQX and NBQX on the spatial distribution of synchrony was investigated.

The basic spatial distribution of CS synchrony under control conditions is shown in Figure 7. In these plots the relative locations of the recording electrodes are represented by circles whose areas are proportional to the amount of synchronous CS activity between the cell at each of the positions and the reference cell $\mathrm{M}$, and synchronous is defined as the onsets of CSs in two cells occurring within $1 \mathrm{msec}$ of each other. Synchronous CS activity displayed a rostrocaudal banding pattern. That is, cells within the same parasagittal strip tended to have the highest level of synchronization, and for cells located in different parasagittal planes, the level of synchronization fell off as a function of the mediolateral distance between the cells, consistent with previous reports (Sasaki et al., 1989; Sugihara et al., 1993). This organization was observed whether CS synchrony was measured using crosscorrelation coefficients (Fig. $7 A$ ) or percentages (synchronous spikes between cell $\mathrm{M}$ and the compared cell per spikes of cell $\mathrm{M}$ ) (Fig. $7 B$ ). In general, because of the similarity of CS firing rates between cells, the two measures of synchrony agreed quite well (Fig. 7C). Because of the agreement of the two measures and the fact that the correlation coefficient measure allows the relationship between the cells of each cell pair to be characterized by a single value, this measure of synchrony will be used for the remainder of the paper.

The results from an experiment in which CS activity was recorded from 29 Purkinje cells simultaneously are shown in Figure 8. In control conditions, the CS activity of cell $\mathrm{M}$ was more strongly synchronized with the CS activity of cells located within a narrow (250- $\mu \mathrm{m}$-wide), rostrocaudally oriented strip of cortex than with the CS activity of cells located outside of this band (Fig. $8 A$ ). Injection of Ringer's solution to the IO produced virtually no change in the pattern of synchronous CS activity, indicating that the injection procedure itself did not cause alterations in the pattern of synchrony (Fig. $8 \mathrm{~B}$ ). Intraolivary injection of CNQX did not eliminate CS synchrony (Fig. $8 C$ ), as would be expected if the synchrony derived from synchronous afferent activity to the IO. Instead the pattern of CS synchrony remained similarly organized to that of the control and Ringer's solution conditions. However, subtle changes in the synchrony distribution could be observed; namely, the synchronization of neighboring cells was generally increased, whereas that of more widely separated cells was decreased, from control levels (Fig. 8A,C).

Similar results were obtained on average regardless of the particular reference cell used to generate the synchrony maps. As shown in Figure 9, $A$ and $B$, intraolivary injections of CNQX or NBQX tended to increase the CS synchrony of cells located at small mediolateral separation distances $(<500 \mu \mathrm{m})$ and/or decrease the CS synchrony of cells more widely separated $(\geq 500$ $\mu \mathrm{m})$. In contrast, injections of Ringer's solution to the IO did not change the distribution of CS synchrony (Fig. 9C). The effects of the injections on the synchrony distribution are most clearly seen by plotting the difference in cross-correlation values between the two conditions as a function of mediolateral distance between the cells, as shown for these experiments in Figure 9, $A 2, B 2$, and $C 2$. Similar results were obtained in all the experiments as shown by the plots in Figure 9D, where the average difference in synchrony in control and in CNQX or NBQX (Fig. 9D1) or Ringer's solution (Fig. 9D2) is plotted for all cell pairs in all experiments 

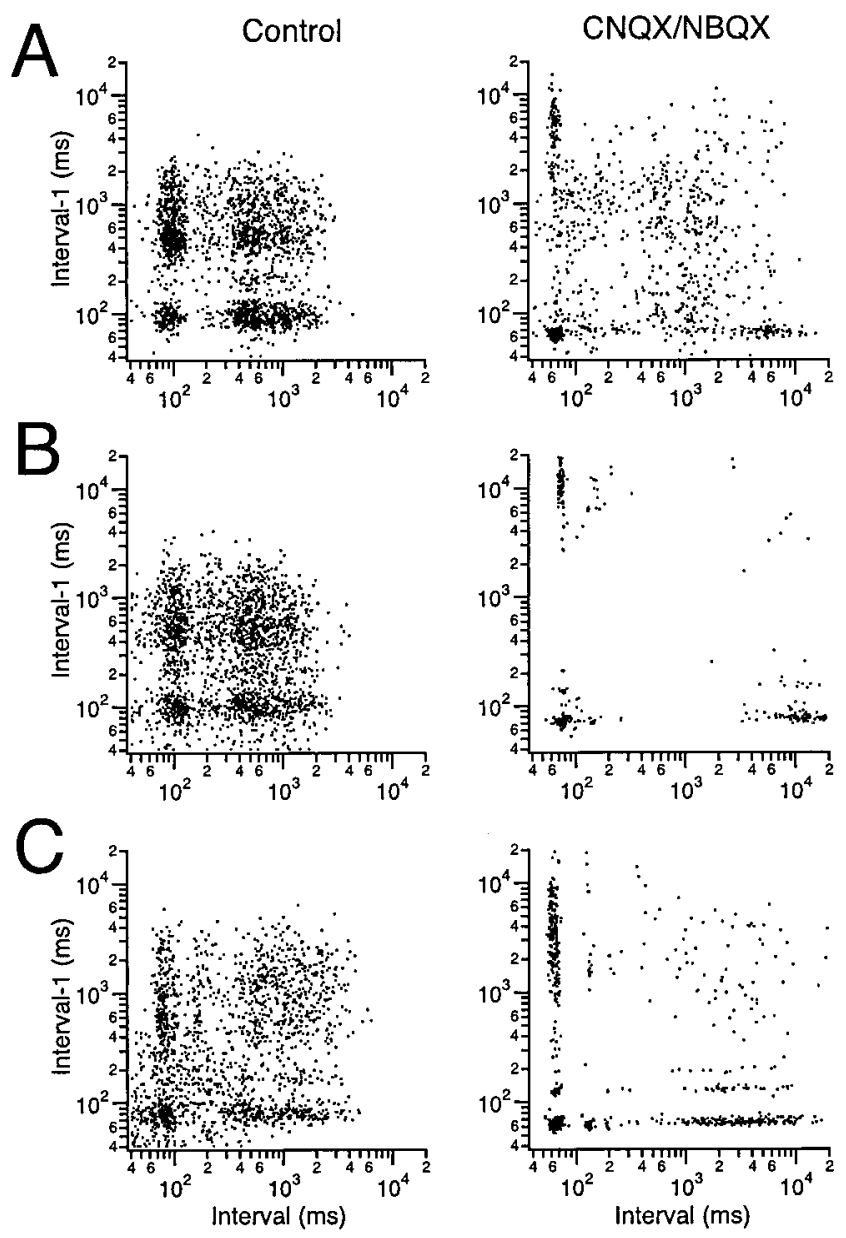

Figure 6. CS activity displays distinct firing modes. Scatter plots were generated by plotting each interspike interval ( $x$-axis) against the previous interspike interval ( $y$-axis). Plots from three cells $(A-C)$ under control conditions (left column) and after intraolivary injection of either CNQX or NBQX (right column) are shown to illustrate the typical patterns that were observed. All plots were generated from 20 min recording sessions.

as a function of the mediolateral distance between the cells of the pair (CNQX or NBQX, $n=1992$ pairs; Ringer's solution, $n=$ 601 pairs). The increase in synchrony after CNQX or NBQX injections between cells with separation distances of $0-250 \mu \mathrm{m}$ was statistically significant $(t=3.57 ; p<0.0005 ; n=580$ pairs; one-sided paired $t$ test) as was the decrease in synchrony for cells separated by $\geq 500 \mu \mathrm{m}(t=3.50 ; p<0.0005 ; n=1412$ pairs; one-sided paired $t$ test). Differences in synchrony between Ringer's solution and control conditions were not significant, with the synchrony for closely spaced cells $(\leq 250 \mu \mathrm{m})$ actually decreasing slightly after the Ringer's solution injections (mediolateral separation $\leq 250 \mu \mathrm{m}, t=-1.72 ; n=186$; mediolateral separation $\geq 500 \mu \mathrm{m}, t=1.27$; $n=415$ ).

\section{Complex spike synchrony during oscillatory and nonoscillatory activity}

The fact that the CNQX or NBQX injections both enhanced CS rhythmicity and modified the spatial distribution of CS synchrony suggested that the two aspects of CS activity may covary under control conditions. Thus, the activity of each cell was divided into oscillatory and nonoscillatory periods. Oscillatory periods were defined as the times during which the interspike intervals fell within the range of $70-135 \mathrm{msec}(7.4-14.3 \mathrm{~Hz})$, and nonoscilla- tory periods were defined as the times when the cell fired with interspike intervals of $800-10,000 \mathrm{msec}(1.25-0.1 \mathrm{~Hz})$. The crosscorrelations of each cell with the other simultaneously recorded cells were then calculated for these two periods. In the four experiments ( $n=120$ cells, 3530 cell pairs) in which this analysis was performed, the average level of synchrony of a cell with other cells more than doubled during its oscillatory periods $(0.0281 \pm$ $0.0010)$ as compared with its nonoscillatory periods $(0.0121 \pm$ $0.0005)$, a statistically significant increase $(t=13.8 ; p<0.001)$. Moreover, comparison of the spatial distribution of CS synchrony during oscillatory and nonoscillatory activity showed that the major increase in synchrony occurred among cells with small mediolateral separation distances. This is demonstrated by Figure 10, which shows the synchrony of the activity of cell $\mathrm{M}$ with that of each of the 35 other simultaneously recorded cells while cell M displayed either nonoscillatory (Fig. 10A) or oscillatory (Fig. 10B) activity. This fact is further demonstrated by plotting the average synchrony with cell $\mathrm{M}$ as a function of the mediolateral separation between the cells (Fig. 10C). This selective increase in synchronization during oscillatory activity was the typical pattern that was observed, as is shown by the plot of synchrony as a function of mediolateral separation for all cell pairs in this experiment during oscillatory and nonoscillatory activity (Fig. 10D). Thus, during oscillatory activity, whether induced by block of glutamatergic input to the IO or occurring spontaneously, the banding pattern of CS synchrony is enhanced.

\section{DISCUSSION}

The present experiments investigated the role of excitatory glutamatergic inputs to the IO in modulating olivocerebellar activity. By using multiple electrode recording of CS activity and microinjections of the glutamate receptor blockers CNQX or NBQX into the IO, it was demonstrated that major excitatory projections to the IO use glutamate receptors and that the olivocerebellar system can generate spontaneous CS activity that is both synchronized and oscillatory in the absence of glutamatergic excitatory input. In addition, the results suggest that excitatory input to the IO acts to disrupt the rhythmicity of CS activity and modifies the spatial distribution of CS synchrony in a manner that is complementary to that of inhibitory inputs.

\section{Glutamate receptors mediate excitatory drive to the inferior olive}

Electrophysiological studies have demonstrated that excitatory responses of the olivocerebellar system can be evoked from areas throughout the neuraxis (Provini et al., 1968; Allen et al., 1974; Oscarsson and Sjölund, 1974; Sasaki et al., 1975, 1977; Jeneskog, 1981a,b, 1987). Immunohistochemical studies have provided evidence of glutamate receptor subunits throughout the IO (Petralia and Wenthold, 1992; Ambalavanar et al., 1998; Paarmann et al., 2000), suggesting that these excitatory responses could be mediated by glutamate. The present results provide direct evidence that this is the case for descending pathways originating in the motor cortex and for pathways conveying sensory information from the face.

\section{Rhythmic complex spike activity in the absence of excitatory input to the inferior olive}

Some theories of olivocerebellar function imply that olivocerebellar activity is primarily driven by afferent activity. For example, olivocerebellar discharges have been postulated to signal unexpected sensory events during movement as a result of activity in spino-olivary pathways (Miller and Oscarsson, 1970; Oscars- 
Figure 7. Spatial organization of CS synchrony. $A, B$, Spatial distribution of $\mathrm{CS}$ synchrony with regard to reference cell $\mathrm{M}$, as measured by cross-correlation coefficients $(A)$ and by the percentage of synchronous spikes of cell $\mathrm{M}$ with each of the other simultaneously recorded cells $(B)$. In each case (correlation coefficients, percentages) the positions of the circles represent the relative positions of the recording electrodes on crus $2 \mathrm{a}$. The area of each circle is proportional to the degree of synchrony between cell $\mathrm{M}$ and the cell located at that position. Scale at bottom right of figure gives calibration for both measures. $C$, The average level of synchronization between cell $\mathrm{M}$ and other cells plotted as a function of the mediolateral separation between the cells. Bin size equaled $1 \mathrm{msec}$ for all analyses, and session duration was $20 \mathrm{~min}$. Correl. Coeff., Correlation coefficient; Mediolat., mediolateral.
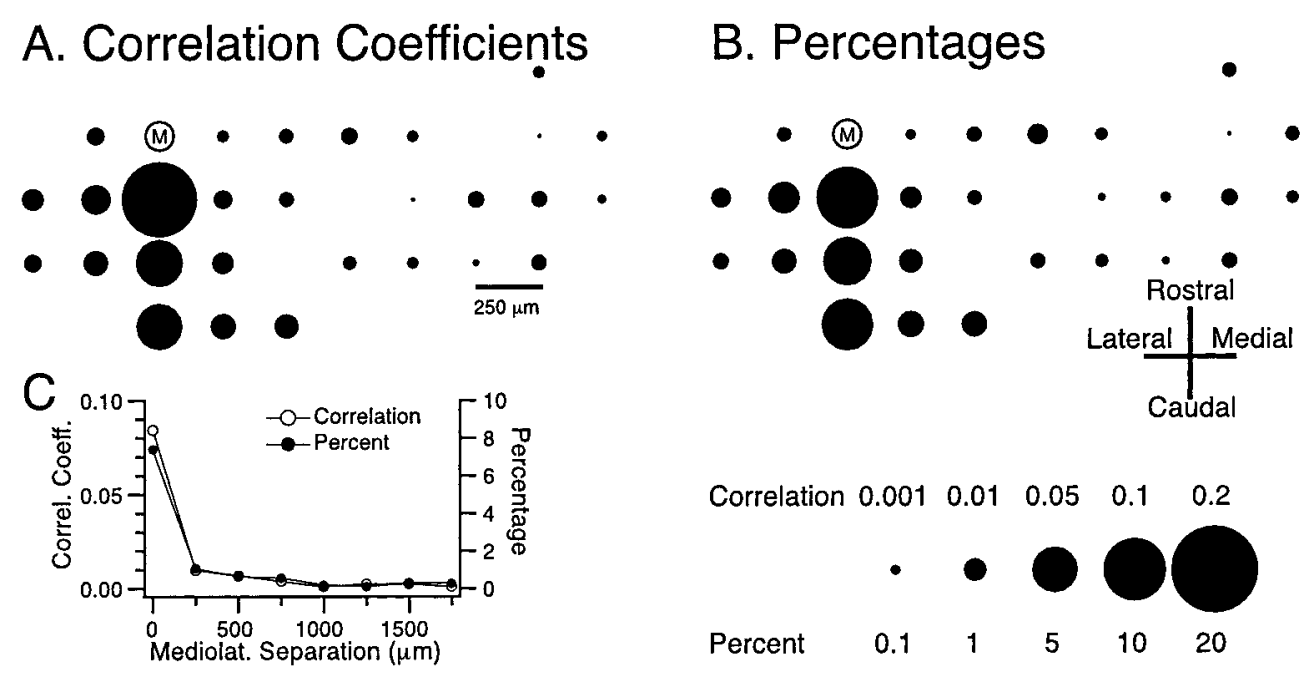

A. Control

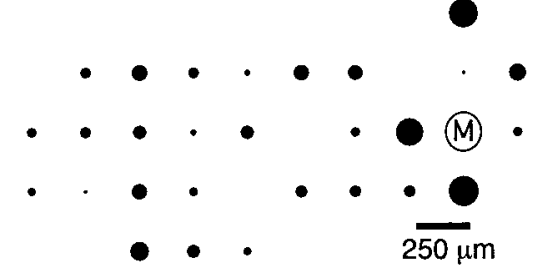

\section{B. Ringers}

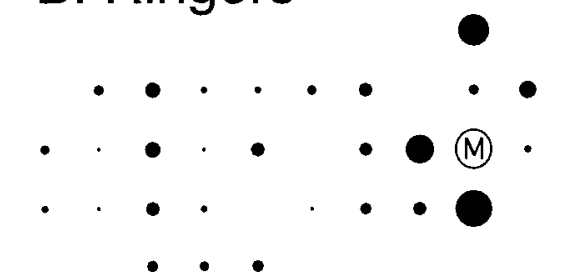

\section{CNQX}

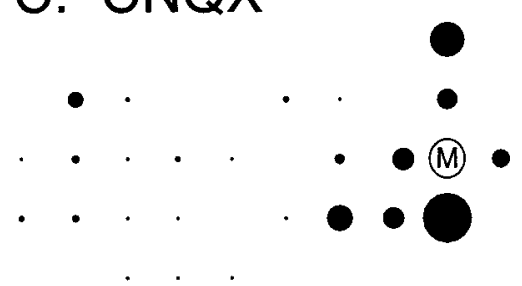

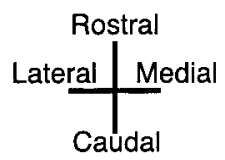
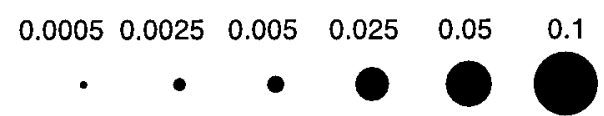

Figure 8. Complex spike synchrony persists after intraolivary CNQX injections. Spatial maps of synchronous CS activity with respect to cell M in control $(A)$ and during injection of Ringer's solution $(B)$ and CNQX $(C)$ to the inferior olive. Circles represent the positions of the recording electrodes on crus 2a. The area of each circle is proportional to the synchrony (i.e., zero-time cross-correlation coefficient) between the CS activity of the cell located at that position and the CS activity of cell M. Time bin for analysis was $1 \mathrm{msec}$. Recording periods were $20 \mathrm{~min}$ for each condition. Scale at bottom gives calibration for $A-C$.

son, 1980) or to carry signals related to the unconditioned stimulus in associative-learning paradigms (Thompson and Krupa, 1994). In contrast, other investigators have favored a theory in which the olivocerebellar system plays a role in the timing of motor outputs, a role that, although not excluding activation of the olivocerebellar system by afferent activity, focuses on the intrinsic ability of this system to generate oscillatory activity (Llinás, 1991; Lang, 1995). The present results show that rhythmic CS activity persists after block of excitatory drive to the IO, supporting the idea of IO neurons acting as oscillators. Nevertheless, blocking excitatory input did reduce the CS firing rate by approximately half, which suggests that some spontaneous CS activity is driven by afferent volleys to the IO. Although some of this reduction may simply be the result of an imbalance in the net tonic excitatory and inhibitory drives to the IO (i.e., with the loss of tonic excitation, inhibitory GABAergic afferents are unopposed), intraolivary injection of solutions containing both picrotoxin and NBQX also produces decreased CS firing rates (E. J. Lang, unpublished observations), suggesting that such an imbalance does not completely explain the decreased CS firing rate. Thus, olivocerebellar activity may be derived from both intrinsic oscillatory mechanisms and external sources.

Interspike interval plots indicate that CS activity displays distinct firing modes, which may correspond to this dual origin of olivocerebellar activity. That is, under control conditions CS activity displayed both oscillatory and nonoscillatory firing patterns, whereas after block of excitatory inputs primarily the oscillatory activity remained. Thus, intrinsically derived olivocerebellar activity appears to be oscillatory, whereas CS activity resulting from excitatory IO afferents tends to have a more random organization.

Under in vitro conditions IO neurons display spontaneous subthreshold oscillations in their resting potential (Benardo and Foster, 1986; Llinás and Yarom, 1986; Lampl and Yarom, 1993). These oscillations, which are synchronized across IO cells, could provide the substrate for the synchronous rhythmic CS activity that is observed in vivo. However, normally CS activity recorded from anesthetized or awake animals displays transient rhythmicity (two to three cycles) (Bell and Kawasaki, 1972; Sasaki et al., 1989; Lang et al., 1997, 1999), whereas the subthreshold oscillations are sustained for many cycles (Benardo and Foster, 1986; Llinás and Yarom, 1986). The present results suggest that this difference may reflect the disruption of the subthreshold oscillations by excitatory input to the IO. Indeed, excitatory inputs to the IO are largely absent under slice conditions in which sustained oscillations are observed, and this situation is approximated by the glutamate blocker injections in the present experiments, which also produce sustained oscillatory CS activity. In agree- 

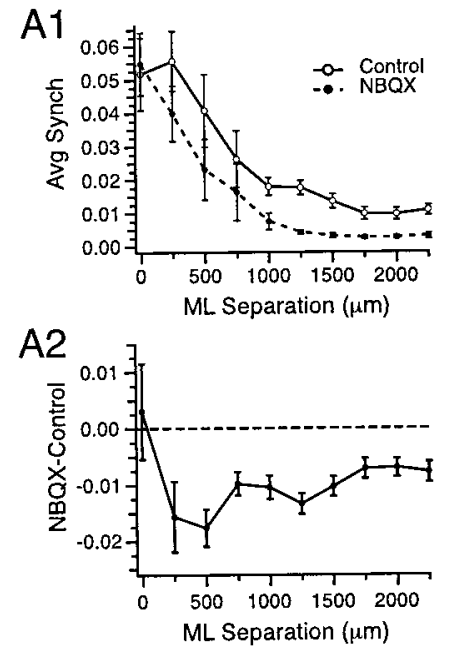
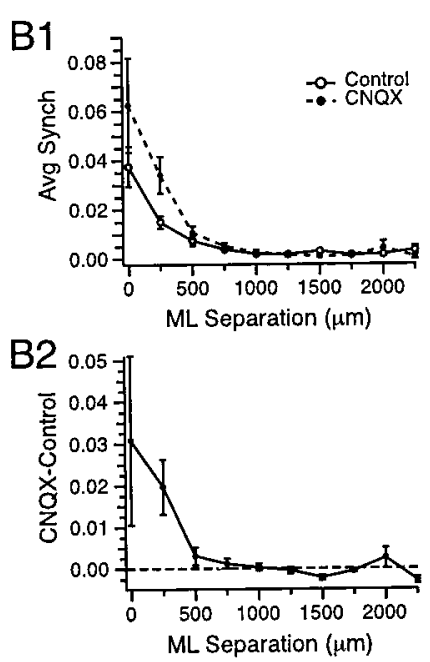
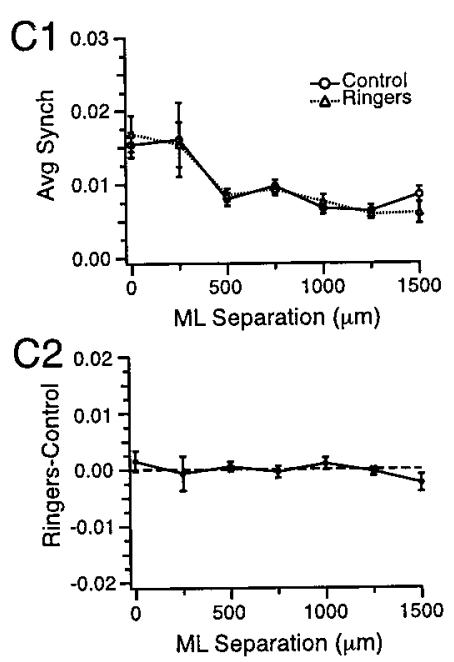
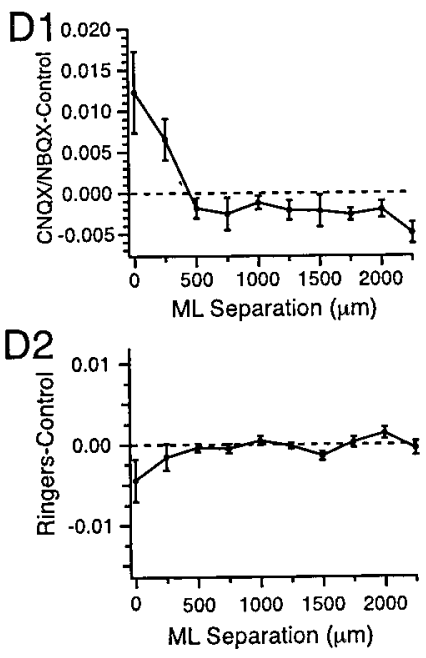

Figure 9. Effect of CNQX or NBQX injections on the spatial distribution of CS synchrony. A1, B1, C1, The average level of CS synchrony plotted as a function of the mediolateral separation distance between cell pairs for three experiments in which NBQX (A1), CNQX (B1), or Ringer's solution ( $C 1)$ was injected into the inferior olive. The plots were generated by calculating the level of synchrony (zero-time cross-correlation coefficient) for all cell pairs and then sorting the pairs according to the mediolateral distance separating the cells. $A 2, B 2$, $C 2$, Plots of the corresponding differences in synchrony between the two conditions in each experiment. D1, Plots of synchrony differences between the CNQX or NBQX condition and control as a function of mediolateral separation for all cells in seven experiments. D2, Same as D1 for synchrony differences between Ringer's solution and control conditions. Error bars are SEM. Time bin for analysis was $1 \mathrm{msec}$. Recording periods were $20 \mathrm{~min}$ for each condition. $M L$, Mediolateral.

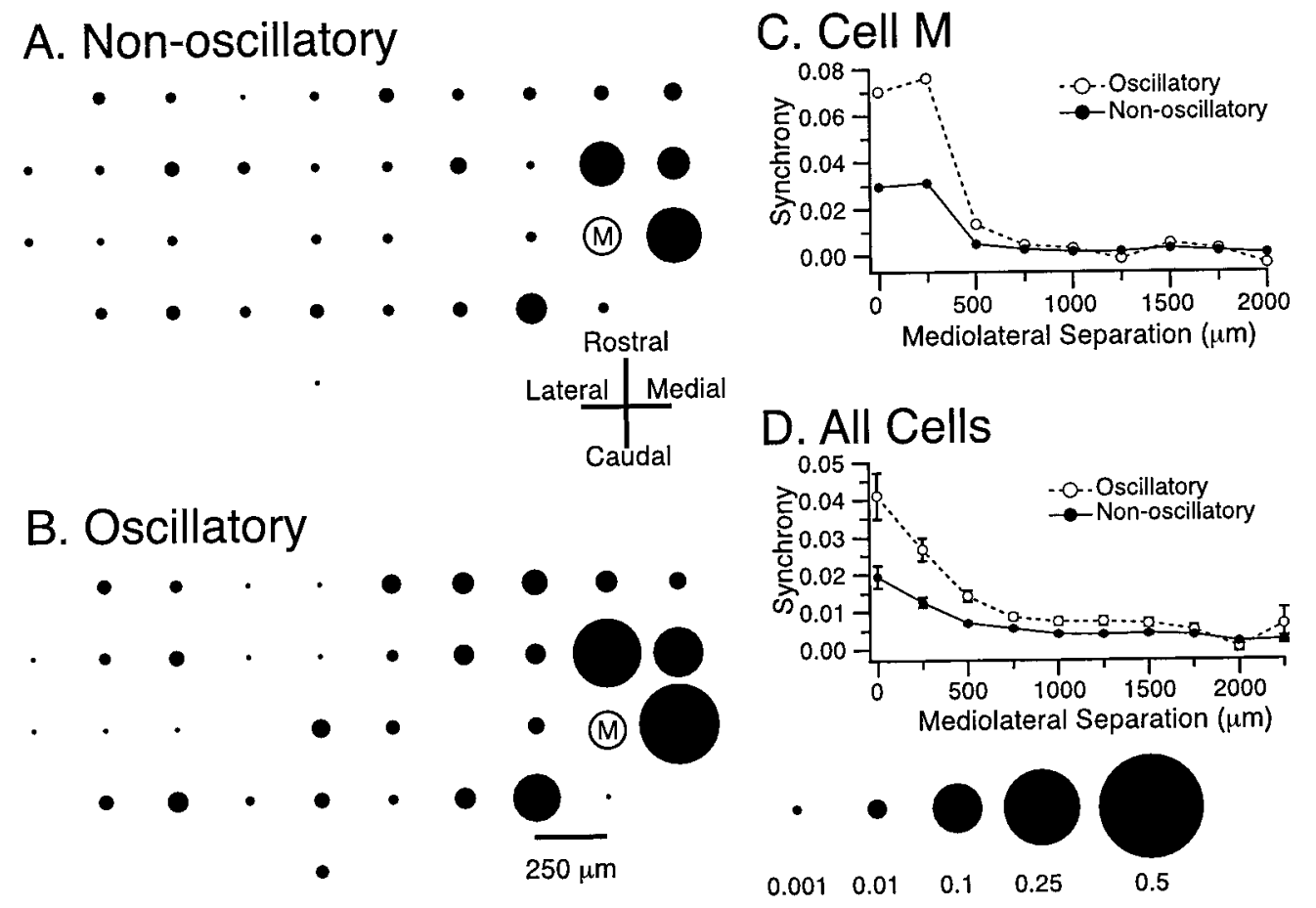

Figure 10. Enhancement of the banding pattern of synchronous $C S$ activity during rhythmic firing. $A, B$, Spatial pattern of CS synchrony with regard to cell $\mathrm{M}$ while cell $\mathrm{M}$ was displaying nonoscillatory $(A)$ and oscillatory $(B)$ $\mathrm{CS}$ activity. Note the preferential increase in synchronization for cells located close to cell M. Scale at bottom right of figure gives calibration for $A$ and $B$. $C$, The average level of synchrony between cell $\mathrm{M}$ and the other cells plotted as a function of the mediolateral separation distance between cell $\mathrm{M}$ and the compared cell for the periods when cell $\mathrm{M}$ displayed oscillatory (open circles) and nonoscillatory ( filled circles) CS activity. D, Plot of average level of synchrony as a function of mediolateral separation between the cells in each pair. The average was obtained by considering all possible cell pairs. Error bars are SEM. ment with this idea, electrical shocks applied to IO slices temporarily abolish subthreshold oscillations in IO neurons (Benardo and Foster, 1986; Llinás and Yarom, 1986).

In addition to becoming more sustained, rhythmic CS activity displayed higher oscillation frequencies after block of glutamatergic neurotransmission. This shift likely reflects a hyperpolarization of IO neurons because of loss of tonic excitatory input. A similar phenomenon has been demonstrated in vitro in which the resonant frequencies of IO neurons shifted to higher frequencies when the cells were hyperpolarized and may be explained by the fact that hyperpolarization of IO neurons decreases activation of dendritic $\mathrm{Ca}^{+2}$ conductances, which in turn shortens the afterhyperpolarization (Llinás and Yarom, 1986). These results are also consistent with, and complementary to, previous findings that blocking GABAergic inhibition to the IO, and thereby presumably depolarizing IO neurons, slows the oscillation frequency of CS activity (Lang et al., 1996).

\section{Synchronous CS activity in the absence of excitatory input to the inferior olive}

Multiple electrode recordings have demonstrated that spontaneous CS activity of Purkinje cells within rostrocaudally oriented 
strips of cortex is synchronized (Sasaki et al., 1989; Sugihara et al., 1993; Lang et al., 1999). The basis of this synchronization has been proposed to be electrotonic coupling of IO neurons via gap junctions that primarily connect their dendritic spines within structures known as glomeruli (Llinás, 1974). Much evidence has been obtained to demonstrate the coupling of IO neurons (Llinás et al., 1974; Sotelo et al., 1974; Llinás and Yarom, 1981a; Benardo and Foster, 1986). Nevertheless, the extent to which synchronous $\mathrm{CS}$ activity results from electrotonic coupling of IO neurons as opposed to synchronization of excitatory activity in IO afferents has not been determined previously. Indeed, the latter possibility must be considered because strong sensory stimuli can evoke synchronous CS responses. However, the present experiments demonstrate that synchronous CS activity remains after block of excitatory IO afferents. Moreover, the overall level and distribution of CS synchrony after block of glutamatergic input were similar to those under control conditions. Thus, the present results suggest that the synchrony of spontaneous CS activity is primarily caused by electrotonic coupling of IO neurons.

\section{Inferior olivary afferents modulate the efficacy of electrotonic coupling}

Despite the IO having one of the highest densities of neuronal gap junctions in the nervous system (Sotelo et al., 1974; de Zeeuw et al., 1995), synchronous CS activity is normally observed mainly among small groups of Purkinje cells lying within the same $\sim 250$ - $\mu \mathrm{m}$-wide parasagittal strip of cortex. This limited distribution is thought to result from modulation of the efficacy of the electrotonic coupling by afferents that synapse adjacent to the gap junctions within the glomeruli (Llinás et al., 1974; Sotelo et al., 1974). Approximately half of these synapses are GABAergic (de Zeeuw et al., 1989) and likely have an important role in determining the distribution of synchronous CS activity, because eliminating GABAergic activity within the IO leads to widespread synchronization of CS activity (Lang et al., 1996).

Although the neurotransmitters of the remaining intraglomerular terminals have not been identified, the majority are likely to be glutamatergic, because terminals containing other transmitters tend to synapse outside the glomeruli (Wiklund et al., 1981; King et al., 1984; Toonen et al., 1998). In particular, for the rostral medial accessory olive, a major source of climbing fibers to crus 2a (Buisseret-Delmas and Angaut, 1993), the cells giving rise to the non-GABAergic intraglomerular terminals are located in the mesodiencephalon, particularly in the nucleus of Darkschewitsch (de Zeeuw et al., 1989), and the projection cells of this nucleus likely use excitatory amino acids as neurotransmitters (Onodera and Hicks, 1995).

The presence of glutamatergic intraglomerular terminals suggests that glutamate plays a role in modulating CS synchrony. The present results suggest that this role is complementary to that of GABA. That is, whereas block of GABAergic input disrupts the banding pattern (Lang et al., 1996), block of glutamatergic input enhances it. This enhancement occurred because CNQX and NBQX injections increased CS synchrony among cells within the same parasagittally oriented strip of cortex while also reducing CS synchrony among cells located in different parasagittal cortical strips. An explanation for this somewhat paradoxical result may lie in the anatomical organization of the IO and in the fact that loss of glutamatergic synaptic activity should both increase the electrical compactness of IO neurons and hyperpolarize them. Inferior olivary neurons are clustered into groups whose dendritic trees overlap extensively and therefore should be strongly cou- pled by gap junctions (Sotelo et al., 1974). The increased electrical compactness would mean that tightly coupled cells within a cluster would function in more of an all-or-none manner. In contrast, with relatively few gap junctions linking cells of different clusters, current flow between cell clusters may not be sufficient to overcome the hyperpolarized state of IO neurons, thereby reducing synchronized activity among IO neurons belonging to separate clusters.

\section{REFERENCES}

Allen GI, Azzena GB, Ohno T (1974) Cerebellar Purkinje cell responses to inputs from sensorimotor cortex. Exp Brain Res 20:239-254.

Ambalavanar R, Ludlow CL, Wenthold RJ, Tanaka Y, Damirjian M, Petralia RS (1998) Glutamate receptor subunits in the nucleus of the tractus solitarius and other regions of the medulla oblongata in the cat. J Comp Neurol 402:75-92.

Bal T, McCormick DA (1997) Synchronized oscillations in the inferior olive are controlled by the hyperpolarization-activated cation current $\mathrm{I}_{\mathrm{h}}$. J Neurophysiol 77:3145-3156.

Bell CC, Kawasaki T (1972) Relations among climbing fiber responses of nearby Purkinje cells. J Neurophysiol 35:155-169.

Benardo LS, Foster RE (1986) Oscillatory behavior in inferior olive neurons: mechanisms, modulation, cell aggregates. Brain Res Bull 17:773-784

Bleasel AF, Pettigrew AG (1992) Development and properties of spontaneous oscillations of the membrane potential in inferior olivary neurons in the rat. Dev Brain Res 65:43-50.

Buisseret-Delmas C, Angaut P (1993) The cerebellar olivocorticonuclear connections in the rat. Prog Neurobiol 40:63-87.

Clements JA, Nimmo WS (1981) Pharmacokinetics and analgesic effect of ketamine in man. Br J Anaesth 53:27-30.

Cohen ML, Chan S-L, Way WL, Trevor AJ (1973) Distribution in the brain and metabolism of ketamine in the rat after intravenous administration. Anesthesiology 39:370-376.

Crill WE (1970) Unitary multiple-spiked responses in cat inferior olive nucleus. J Neurophysiol 33:199-209.

de Zeeuw CI, Holstege JC, Ruigrok TJH, Voogd J (1989) Ultrastructural study of the GABAergic, cerebellar, and mesodiencephalic innervation of the cat medial accessory olive: anterograde tracing combined with immunocytochemistry. J Comp Neurol 284:12-35.

de Zeeuw CI, Hertzberg EL, Mugnaini E (1995) The dendritic lamellar body: a new neuronal organelle putatively associated with dendrodendritic gap junctions. J Neurosci 15:1587-1604.

Ebert B, Mikkelsen S, Thorkildsen C, Borgbjerg FM (1997) Norketamine, the main metabolite of ketamine, is a non-competitive NMDA receptor antagonist in the rat cortex and spinal cord. Eur J Pharmacol 333:99-104.

Gerstein GL, Kiang WY (1960) An approach to the quantitative analysis of equations of electrophysiological data from single neurons. Biophys $\mathrm{J} 1: 15-28$

Jeneskog T (1981a) On climbing fibre projection to cerebellar paramedian lobule activated from the mesencephalon in the cat. Brain Res 211:135-140.

Jeneskog T (1981b) Identification of a tecto-olivocerebellar path to posterior vermis in the cat. Brain Res 211:141-145.

Jeneskog T (1987) Termination in posterior and anterior cerebellum of a climbing fiber pathway activated from the nucleus of Darkschewitsch in the cat. Brain Res 412:185-189.

King JS, Ho RH, Burry RW (1984) The distribution and synaptic organization of serotoninergic elements in the inferior olivary complex of the opossum. J Comp Neurol 227:357-368.

Lampl I, Yarom Y (1993) Subthreshold oscillations of the membrane potential: a functional synchronizing and timing device. J Neurophysiol 70:2181-2186.

Lang EJ (1995) Synchronicity, rhythmicity and movement: the role of the olivocerebellar system in movement. PhD thesis, New York University, School of Medicine.

Lang EJ, Sugihara I, Llinás R (1996) GABAergic modulation of complex spike activity by the cerebellar nucleoolivary pathway in rat. J Neurophysiol 76:255-275.

Lang EJ, Sugihara I, Llinás R (1997) Differential roles of apamin- and charybdotoxin-sensitive $\mathrm{K}^{+}$conductances in the generation of inferior olive rhythmicity in vivo. J Neurosci 17:2825-2838.

Lang EJ, Sugihara I, Welsh JP, Llinás R (1999) Patterns of spontaneous Purkinje cell complex spike activity in the awake rat. J Neurosci 19:2728-2739.

Llinás R (1974) Eighteenth Bowditch lecture. Motor aspects of cerebellar control. Physiologist 17:19-46.

Llinás R (1991) The noncontinuous nature of movement execution. In: Motor control: concepts and issues (Humphrey DR, Freund H-J, eds), pp 223-242. New York: Wiley. 
Llinás R, Sasaki K (1989) The functional organization of the olivocerebellar system as examined by multiple Purkinje cell recordings. Eur J Neurosci 1:587-602.

Llinás R, Yarom Y (1981a) Electrophysiology of mammalian inferior olivary neurones in vitro. Different types of voltage-dependent ionic conductances. J Physiol (Lond) 315:549-567.

Llinás R, Yarom Y (1981b) Properties and distribution of ionic conductances generating electroresponsiveness of mammalian inferior olivary neurones in vitro. J Physiol (Lond) 315:569-584.

Llinás R, Yarom Y (1986) Oscillatory properties of guinea-pig inferior olivary neurones and their pharmacological modulation: an in vitro study. J Physiol (Lond) 376:163-182.

Llinás R, Baker R, Sotelo C (1974) Electrotonic coupling between neurons in cat inferior olive. J Neurophysiol 37:560-571.

Martin D, Lodge D (1985) Ketamine acts as a non-competitive $N$-methyl-D-aspartate antagonist on frog spinal cord in vitro. Neuropharmacology 24:999-1003.

Miller S, Oscarsson O (1970) Termination and functional organization of spino-olivo-cerebellar paths. In: The cerebellum in health and disease (Fields WS, Willis WD, eds), pp 172-200. St. Louis: Green.

Onodera S, Hicks TP (1995) Patterns of transmitter labelling and connectivity of the cat's nucleus of Darkschewitsch: a wheat germ agglutinin-horseradish peroxidase and immunocytochemical study at light and electron microscopical levels. J Comp Neurol 361:553-573.

Oscarsson O (1980) Functional organization of olivary projection to the cerebellar anterior lobe. In: The inferior olivary nucleus: anatomy and physiology (Courville J, De Montigny C, Lamarre Y, eds), pp 279-289. New York: Raven.

Oscarsson O, Sjölund B (1974) Identification of 5 spino-olivocerebellar paths ascending through the ventral funiculus of the cord. Brain Res 69:331-335.

Paarmann I, Frermann D, Keller BU, Hollmann M (2000) Expression of 15 glutamate receptor subunits and various splice variants in tissue slices and single neurons of brainstem nuclei and potential function implications. J Neurochem 74:1335-1345.

Paré D, LeBel E, Lang EJ (1997) Differential impact of miniature synaptic potentials on the soma and dendrites of pyramidal neurons in vivo. J Neurophysiol 78:1735-1739.

Paxinos G, Watson C (1998) The rat brain in stereotaxic coordinates, 4th Edition. Sydney: Academic.

Pellerin J-P, Parent M-T, Valiquette C, Lamarre Y (1997) Rhythmic climbing fiber responses in the cerebellum of the awake behaving monkey. Soc Neurosci Abstr 23:1286.

Petralia RS, Wenthold RJ (1992) Light and electron immunocytochem- ical localization of AMPA-selective glutamate receptors in the rat brain. J Comp Neurol 318:329-354.

Petralia RS, Yokotani N, Wenthold RJ (1994) Light and electron microscope distribution of the NMDA receptor subunit NMDAR1 in the rat nervous system using a selective anti-peptide antibody. J Neurosci 14:667-696.

Provini L, Redman S, Strata P (1968) Mossy and climbing fibre organization on the anterior lobe of the cerebellum activated by forelimb and hindlimb areas of the sensorimotor cortex. Exp Brain Res 6:216-233.

Sasaki K, Oka H, Matsuda Y, Shimono T, Mizuno N (1975) Electrophysiological studies of the projections from the parietal association area to the cerebellar cortex. Exp Brain Res 23:91-102.

Sasaki K, Oka H, Kawaguchi S, Jinnai K, Yasuda T (1977) Mossy fibre and climbing fibre responses produced in the cerebellar cortex by stimulation of the cerebral cortex in monkeys. Exp Brain Res 29:419-428.

Sasaki K, Bower JM, Llinás R (1989) Multiple Purkinje cell recording in rodent cerebellar cortex. Eur J Neurosci 1:572-586.

Schalm OW, Jain NC, Carroll EJ (1975) Veterinary hematology, 3rd Edition. Philadelphia: Lea and Febiger.

Sotelo C, Llinás R, Baker R (1974) Structural study of inferior olivary nucleus of the cat: morphological correlates of electrotonic coupling. J Neurophysiol 37:541-559.

Sugihara I, Lang EJ, Llinás R (1993) Uniform olivocerebellar conduction time underlies Purkinje cell complex spike synchronicity in the rat cerebellum. J Physiol (Lond) 470:243-271.

Sugihara I, Lang EJ, Llinás R (1995) Serotonin modulation of inferior olivary oscillations and synchronicity: a multiple-electrode study in the rat cerebellum. Eur J Neurosci 7:521-534.

Thompson RF, Krupa DJ (1994) Organization of memory traces in the mammalian brain. Annu Rev Neurosci 17:519-549.

Toonen M, Van Dijken H, Holstege JC, Ruigrok TJH, Koekkoek SKE, Hawkins RK, Teune TM, Burg JVD, De Zeeuw CI (1998) Light microscopic and ultrastructural investigation of the dopaminergic innervation of the ventrolateral outgrowth of the rat inferior. Brain Res 802:267-273.

Welsh JP, Lang EJ, Sugihara I, Llinás R (1995) Dynamic organization of motor control within the olivocerebellar system. Nature 374:453-457.

Wiklund L, Sjolund B, Bjorklund A (1981) Morphological and functional studies on the serotoninergic innervation of the inferior olive. J Physiol (Paris) 77:183-186.

Wylie DR, De Zeeuw CI, Simpson JI (1995) Temporal relations of the complex spike activity of Purkinje cell pairs in the vestibulocerebellum of rabbits. J Neurosci 15:2875-2887. 